\title{
Low temperature mid-infrared cross-sections for peroxyacetyl nitrate (PAN) vapour
}

\author{
G. Allen ${ }^{1}$, J. J. Remedios ${ }^{1}$, and K. M. Smith ${ }^{2}$ \\ ${ }^{1}$ EOS, Space Research Centre, Department of Physics and Astronomy, University of Leicester, Leicester, LE1 7RH, UK \\ ${ }^{2}$ Space Science and Technology Department, Rutherford Appleton Laboratory, Didcot, Oxon, OX11 0QX, UK
}

Received: 7 June 2005 - Published in Atmos. Chem. Phys. Discuss.: 8 August 2005

Revised: 19 October 2005 - Accepted: 24 October 2005 - Published: 24 November 2005

\begin{abstract}
Laboratory absorption spectra of peroxyacetyl nitrate $\left(\mathrm{PAN}, \mathrm{CH}_{3} \mathrm{C}(\mathrm{O}) \mathrm{OONO}_{2}\right)$ vapour have been measured in the mid-infrared range $550 \mathrm{~cm}^{-1}$ to $1400 \mathrm{~cm}^{-1}(18.2$ to $7.14 \mu \mathrm{m})$ at both $250 \mathrm{~K}$ and $273 \mathrm{~K}$, using a Fourier transform infrared spectrometer at a nominal spectral resolution of $0.25 \mathrm{~cm}^{-1}$ (unapodised). In addition, the $1600 \mathrm{~cm}^{-1}$ to $2200 \mathrm{~cm}^{-1}$ (6.25 to $\left.4.54 \mu \mathrm{m}\right)$ spectral region has been measured at $250 \mathrm{~K}$. Cross-sectional data at each temperature, as well as integrated band intensities and peak infrared absorptivities for nine absorption bands of PAN in this spectral range, have been derived from a total of twelve separately measured PAN transmission spectra. A general increase in the peak absorption cross-section for all bands is noted with decreasing temperature, with cross-sectional increases in the range $6 \%$ (for the $1842 \mathrm{~cm}^{-1}$ band) and $30 \%$ (for the $991 \mathrm{~cm}^{-1}$ band) at $250 \mathrm{~K}$, relative to those previously reported at $295 \mathrm{~K}$. Differences in integrated band intensities range from $-22 \%$ to $+16 \%$ for the $1741 \mathrm{~cm}^{-1}$ and $991 \mathrm{~cm}^{-1}$ bands respectively over the same temperature range. These new absorption cross-sections for PAN are the first to be reported at temperatures below $295 \mathrm{~K}$, allowing the possibility of improved retrievals of the atmospherically important PAN species from remotely sensed infrared spectra of the cold upper troposphere. These new cross-sectional data accompany this paper as an electronic supplement.
\end{abstract}

\section{Introduction}

PAN is one of the most important odd-nitrogen $\left(\mathrm{NO}_{\mathrm{y}}\right)$ compounds in the atmosphere, both through its direct influence on the oxidising power of the atmosphere and also through its indirect role as a reservoir species for active nitrogen (Singh and Hanst, 1981; Singh, 1987). Furthermore, PAN has of-

Correspondence to: G. Allen

(ga15@le.ac.uk) ten been noted to be the most abundant NOy species in the middle and upper troposphere in pollution events (Roberts, 1990; Roberts et al., 2004).

PAN is formed in the atmosphere by organic photochemistry in the presence of $\mathrm{NO}_{2}$ with an atmospheric lifetime dominated by thermolysis in the lower troposphere $(<7 \mathrm{~km})$ and photolysis in the upper troposphere (Talukdar et al., 1995). It is the relatively long lifetime (of the order of months) of PAN in the cold upper troposphere that makes this species an important global transport vehicle for $\mathrm{NO}_{2}$. PAN concentrations as high as $650 \mathrm{pptv}$ (at $10 \mathrm{~km}$ altitude) have been observed in pollution plumes such as those measured by Roberts et al. (2004) in Asian pollution outflow.

Current measurements of PAN are limited to in situ sampling during specialised campaigns such as those described by Emmons et al. (2000), with uncertainties of the order $30 \%$ at typical upper troposphere (UT) concentrations (Tanimoto et al., 1999). New satellite missions such as the infrared solar occulation Atmospheric Chemistry Experiment (ACE), launched in August 2003 (see Bernath et al. (2005) for further details), and the infrared limb-sounding Michelson Interferometer for Passive Atmospheric Sounding (MIPAS) described by Fischer and Oelhaf (1996) and launched onboard Envisat in March 2002, could provide an alternative means to remotely detect trace organic species such as PAN by virtue of their characteristic infrared signature; and to determine global concentrations. The potential retrieval of PAN concentration data from satellite-derived spectra requires accurate laboratory cross-sections for PAN as well as for all other compounds exhibiting influence in the spectral window over which such retrieval is performed. Furthermore, this reference spectral data must be measured at temperatures and pressures appropriate to the atmospheric profile.

In this paper, we report the first data for the infrared absorption cross-sections of PAN vapour recorded at temperatures below $291 \mathrm{~K}$, complementing a room temperature dataset reported previously by Allen et al. (2005). These new

(C) 2005 Author(s). This work is licensed under a Creative Commons License. 
Table 1. Sample and measurement parameters for recorded spectra employed in the calculation of infrared data for PAN.

\begin{tabular}{ccl}
\hline Temp. / K & Filter passband $/ \mathrm{cm}^{-1}$ & Sample Pressure / mb \\
\hline 273 & $550-1400$ & $0.19,0.37,0.38,0.39,0.41$ \\
250 & $550-1400$ & $0.34,0.39,0.40,0.41,0.41$ \\
& $1600-2200$ & $0.48,1.30$ \\
\hline
\end{tabular}

spectral data for PAN will allow greater confidence in the identification and potentially the retrieval of PAN concentration information for the colder temperatures of the free and upper troposphere. Atmospheric detection limits for PAN by this method are yet to be ascribed due to the variabilityin the performance of different infrared instruments (e.g. instrument noise and atmospheric pathlength). These laboratory measurements will allow such instrument-specific studies to be undertaken in the future.

\section{Experimental method}

PAN is a relatively heavy (141 amu) asymmetric top molecule with twenty-seven fundamental vibration modes, of which fifteen are expected to influence the 550 to $2200 \mathrm{~cm}^{-1}$ spectral region. Nominal band centres for PAN absorption bands used in this work are based on band assignments made by Bruckmann and Willner (1983). The strong 794 and $1163 \mathrm{~cm}^{-1}$ PAN bands are expected to be of key interest for remote-sensing applications given their strong spectral influence in these atmospheric window regions.

Spectra presented here were recorded using a Bruker IFS 120HR Fourier transform infrared (FTIR) spectrometer at the Molecular Spectroscopy Facility, Rutherford Appleton Laboratory, UK. A Fourier transform spectrometer is employed here for its ability to simultaneously measure the wide spectral range required for the broad absorption bands of PAN (typically greater than $40 \mathrm{~cm}^{-1}$ ). An evacuated $26.1 \mathrm{~cm}$ path length glass absorption cell equipped with wedged potassium bromide windows was interfaced with a customised gas handling vacuum line. Further details of the experimental procedure and sample generation are given by Allen et al. (2005). A short description is provided here, highlighting aspects of relevance to these experiments.

A liquid nitrogen-cooled MCT detector (MCT-D360) was used, giving an excellent signal-to-noise ratio over the region of interest (typically better than 500:1 after co-addition at $1740.5 \mathrm{~cm}^{-1}$ and $450: 1$ at worst for the $794.0 \mathrm{~cm}^{-1}$ PAN band). Three overlapping spectral regions in the mid-infrared were measured using a $1 \mathrm{~mm}$ stop-aperture and appropriate optical and electronic filters. The use of optical and electronic filters covering a narrow spectral range improved the signal-to-noise ratio in the measured spectra. Together with a small stop aperture, these filters effectively removed the effects of detector non-linearity, noted to be a problem with MCT detectors (Richardson et al., 1998). Using this method, no evidence of such non-linearity was observed in any of the measurements reported in this work.

PAN samples were prepared by the nitration of peracetic acid in a synthesis based on that described by Gaffney et al. (1984) and were tested for purity (found to be greater than $99 \%$ ) by gas chromatography. At the cold temperatures of these experiments, no spectral evidence of contamination was observed in any measurement, as expected from vapour pressure and sample stability considerations. A summary of the sample and measurement parameters is given in Table 1, with each measurement (50 co-added scans) requiring approximately six minutes. This time was sufficiently small so as to neglect thermal decomposition of the PAN sample (estimated to be less than $0.5 \%$ of sample). Sample emission was not expected at the cold temperatures of these experiments as confirmed by spectral measurement of PAN samples with the infrared source switched off. All spectra were recorded at an instrument spectral resolution of $0.25 \mathrm{~cm}^{-1}$ (where resolution is defined here as 0.9 /maximum optical path difference) and apodised with the Norton-Beer strong function (Norton and Beer, 1976, 1977). Five PAN samples were measured over a pressure range of 0.19 to $0.41 \mathrm{mb}$ at both $273 \mathrm{~K}$ and $250 \mathrm{~K}$ across the spectral range 550 to $1400 \mathrm{~cm}^{-1}$, which is noted to be of major importance for remote-sensing applications. In addition, two PAN samples were measured in the 1600 to $2200 \mathrm{~cm}^{-1}$ spectral region at $250 \mathrm{~K}$ to observe the interesting PAN bands centred at $1741 \mathrm{~cm}^{-1}$ and $1842 \mathrm{~cm}^{-1}$. The upper limit on the potential sample pressure at $250 \mathrm{~K}$ was due to the small saturation vapour pressure of PAN at this temperature (approximately $1.4 \mathrm{mb}$ ) expected from the relationship reported by Bruckmann and Willner (1983).

In order to investigate the potential effects of pressure broadening on PAN spectral bands, a dry nitrogen gas source was used. A dry nitrogen source was chosen to minimize the potential presence of water in the sample cell and consequent unwanted spectral lines. For such measurements, dry nitrogen gas was added to a known cell pressure of pure PAN up to a total cell pressure of $500 \mathrm{mb}$ prior to spectral measurement, again at a spectral resolution of $0.25 \mathrm{~cm}^{-1}$ with 50 co-added scans and over the same spectral range.

Transmission spectra were calculated by ratioing PAN sample spectra with the average of background spectra recorded immediately before and after each sample measurement. The limited pressure range studied has the advantage that PAN bands do not approach saturation ( $>40 \%$ transmission for the strong $1741 \mathrm{~cm}^{-1}$ at $1.3 \mathrm{mb}$ ) at the pathlength used here, and measurements are not therefore expected to be subject to possible non-linearities in the Beer-Lambert law such as described by Chu et al. (1999) at high optical densities.

Resolution of rotational fine structure was not observed in any measurement made in this work. An initial comparison 
Table 2. Peak infrared absorptivities $\left(10^{-1} \mu \mathrm{mol}^{-1} \mathrm{~m}^{-1}, \log\right.$ to base 10) and integrated intensities (atm ${ }^{-1} \mathrm{~cm}^{-2}$ ) for PAN vapour at 250 , 273 and $295 \mathrm{~K}$. Units refer to $1013.25 \mathrm{mb}$ at the nominal temperature. ${ }^{*} 295 \mathrm{~K}$ data taken from work by Allen et al. (2005).

\begin{tabular}{ccccccc}
\hline $\begin{array}{c}\text { Band centre/ } \\
\mathrm{cm}^{-1}\end{array}$ & \multicolumn{2}{c}{$250 \mathrm{~K}$} & \multicolumn{2}{c}{$273 \mathrm{~K}$} & \multicolumn{2}{c}{$295 \mathrm{~K}^{*}$} \\
& Peak Abs. & Band Int. & Peak Abs. & Band Int. & Peak Abs. & Band Int. \\
\hline 606 & $1.89 \pm 0.36$ & $39.0 \pm 3.0$ & $1.81 \pm 0.33$ & $35.9 \pm 2.6$ & $1.55 \pm 0.12$ & $34.2 \pm 1.4$ \\
794 & $13.44 \pm 0.86$ & $272 \pm 11.0$ & $13.20 \pm 0.80$ & $252 \pm 9.0$ & $11.40 \pm 1.0$ & $241 \pm 6.0$ \\
930 & $1.80 \pm 0.17$ & $36.2 \pm 2.9$ & $1.72 \pm 0.26$ & $34.1 \pm 2.5$ & $1.46 \pm 0.12$ & $32.2 \pm 1.2$ \\
991 & $1.34 \pm 0.12$ & $23.4 \pm 2.1$ & $1.24 \pm 0.21$ & $21.5 \pm 1.6$ & $1.03 \pm 0.08$ & $20.1 \pm 0.8$ \\
1055 & $0.78 \pm 0.17$ & $18.4 \pm 1.4$ & $0.70 \pm 0.14$ & $16.9 \pm 1.0$ & $0.62 \pm 0.06$ & $16.0 \pm 0.8$ \\
1163 & $16.77 \pm 1.02$ & $401 \pm 20.0$ & $15.90 \pm 0.96$ & $370 \pm 17.0$ & $14.60 \pm 1.0$ & $356 \pm 8.0$ \\
1302 & $13.01 \pm 0.64$ & $313 \pm 16.0$ & $12.64 \pm 0.74$ & $315 \pm 13$ & $11.40 \pm 0.8$ & $281 \pm 6.0$ \\
1741 & $33.53 \pm 1.64$ & $419 \pm 9.0$ & - & - & $30.20 \pm 3.0$ & $537 \pm 10.0$ \\
1842 & $10.11 \pm 0.77$ & $242 \pm 4.0$ & - & - & $9.50 \pm 1.2$ & $260 \pm 6.0$ \\
\hline
\end{tabular}

of measurements recorded at $0.25 \mathrm{~cm}^{-1}$ and $0.03 \mathrm{~cm}^{-1}$ spectral resolution did not yield any resolution of fine structure or differences in the observed absorption peak intensity. Therefore higher resolution measurements (greater than $0.05 \mathrm{~cm}^{-1}$ ) were not attempted in this study due to concerns over the stability of the sample over longer measurement times (e.g. greater than $1 \mathrm{~h}$ at $0.05 \mathrm{~cm}^{-1}$ nominal resolution).

Sample pressure was monitored by cross-calibrated 10 Torr and 1000 Torr (full-scale) MKS Baratron 390 pressure gauges $(1 \mathrm{Torr}=1.33 \mathrm{mb})$ after prior calibration with a certified aneroid manometer. To avoid decomposition or detonation of the thermally unstable purified PAN sample, the Baratron gauges were operated at room temperature rather than at the nominal $313 \mathrm{~K}$ thermo-regulated operating temperature. The uncertainty in the measured pressure using this method was calculated to be less than $0.7 \%$ of full-scale for the 10 Torr gauge.

The cell was equipped with a thermally insulating jacket and cooled using thermo-regulated nitrogen-cooled liquid ethanol, pumped around the outer surfaces of the cell. Cell temperature was monitored by a series of eight platinum resistance (PT-100) thermometers, attached in thermal contact with the external walls of the absorption cell, giving a typical mean accuracy of better than $0.1 \mathrm{~K}$.

\section{Results}

Using an error-weighted linear least squares regression to the measured absorbance as a function of sample pressure for each spectral point (see Allen et al., 2005 for a further description of this method), absolute absorption cross-sections at each temperature were calculated from the Beer-Lambert law:

$I_{\nu}=I_{0 v} e^{-n \sigma_{v} x}$, where $n$ is the target gas molecular number density (calculated assuming ideal gas behaviour), $\sigma_{v}$ is the absorption cross-section per molecule as a function of wavenumber, $v$; and $x$ is the absorption cell path length. The $I_{v} / I_{\nu 0}$ term defines the transmission spectrum calculated for each measurement. Similarly, integrated band intensities and peak infrared absorptivities were also calculated from error-weighted regression fits to the nominal PAN band area and peak absorbance as a function of pressure respectively. Such error weighting accounts for the small uncertainty due to the measurement accuracy of sample pressure and temperature as well as radiometric errors such as instrumental noise.

Integrated band intensities and peak infrared absorptivities are given in Table 2 at each temperature. Similar results for PAN at room temperature (295 K) from Allen et al. (2005) are also quoted for comparison. The error quoted refers to a two standard deviation uncertainty (95\% confidence level) calculated from fit statistics to the regression as described in more detail by Allen et al. (2005). The addition of dry nitrogen gas to pure PAN samples up to a total cell pressure $\left(\mathrm{PAN}+\mathrm{N}_{2}\right)$ of $500 \mathrm{mb}$ resulted in no significant evidence of broadening of the PAN absorption bands studied in this spectral range and negligible change $(<0.1 \%)$ in calculated band intensities and peak infrared absorptivities confirming similar findings by Tsalkani and Toupance (1989) at room temperature.

There is an observed increase in both peak absorptivity and integrated band intensity with decreasing temperature for all but the 1741 and $1842 \mathrm{~cm}^{-1}$ bands, for which an increase in the peak absorptivity is accompanied by a decrease in the integrated band intensity. A maximum $30 \%$ and minimum $6 \%$ increase is seen at $250 \mathrm{~K}$ for the $991 \mathrm{~cm}^{-1}$ and $1842 \mathrm{~cm}^{-1}$ peak absorptivities respectively, relative to those reported at $295 \mathrm{~K}$. Differences in integrated band intensity at $250 \mathrm{~K}$ range from $+16 \%$ and $-22 \%$ relative to those reported at $295 \mathrm{~K}$ for the $991 \mathrm{~cm}^{-1}$ and $1741 \mathrm{~cm}^{-1}$ bands respectively. 
Table 3. Peak infrared absorption cross-section $\left(\times 10^{-18} \mathrm{~cm}^{2}\right.$ molecule $\left.{ }^{-1}\right)$ at 250,273 and $295 \mathrm{~K}$ for nine PAN absorption bands in the mid-infrared. Errors shown represent the two standard deviation uncertainty calculated from a Beer's law fit at the nominal band centre. $* 295 \mathrm{~K}$ data taken from work by Allen et al. (2005).

\begin{tabular}{cccc}
\hline Band centre $/ \mathrm{cm}^{-1}$ & $295 \mathrm{~K}^{*}$ & $273 \mathrm{~K}$ & $250 \mathrm{~K}$ \\
\hline 606 & $0.18 \pm 0.02$ & $0.21 \pm 0.04$ & $0.22 \pm 0.04$ \\
794 & $0.95 \pm 0.02$ & $1.10 \pm 0.07$ & $1.12 \pm 0.07$ \\
930 & $0.17 \pm 0.01$ & $0.20 \pm 0.03$ & $0.21 \pm 0.03$ \\
991 & $0.10 \pm 0.01$ & $0.12 \pm 0.02$ & $0.13 \pm 0.02$ \\
1055 & $0.08 \pm 0.01$ & $0.09 \pm 0.02$ & $0.10 \pm 0.02$ \\
1163 & $1.21 \pm 0.03$ & $1.32 \pm 0.08$ & $1.39 \pm 0.08$ \\
1302 & $0.92 \pm 0.02$ & $1.02 \pm 0.06$ & $1.05 \pm 0.06$ \\
1741 & $2.39 \pm 0.06$ & - & $2.68 \pm 0.13$ \\
1842 & $0.74 \pm 0.03$ & - & $0.79 \pm 0.06$ \\
\hline
\end{tabular}

The relative uncertainty (within the $95 \%$ confidence level) of the results reported in Table 2 ranges between $4 \%$ at best for the strong $794 \mathrm{~cm}^{-1}$ PAN integrated band intensity and $22 \%$ at worst for the very weak $1055 \mathrm{~cm}^{-1}$ peak absorptivity. The decrease in accuracy for weaker PAN bands is due to the increased uncertainty introduced by baseline noise relative to their weak spectral signatures. For the five strongest PAN absorption bands, relative uncertainty is calculated to be less than $5 \%$ at all temperatures. However, it is noted that due to the assigned uncertainty for each integrated band intensity there is the possibility for overlap at the extremes of the assigned error for intensities calculated at $250 \mathrm{~K}$ and $295 \mathrm{~K}$.

The calculated absorption cross-sections across the spectral range covered at each temperature, are plotted in Fig. 1. Differences in the structure of the 794, 1163, 1741 and $1842 \mathrm{~cm}^{-1}$ bands with decreasing temperature are illustrated in more detail in Fig. 2, with an observed narrowing of these bands seen to be most significant for the 1741 and $1842 \mathrm{~cm}^{-1}$ bands. The full-width at half-maximum (FWHM) of the $1741 \mathrm{~cm}^{-1}$ band is reduced from $20 \mathrm{~cm}^{-1}$ at $295 \mathrm{~K}$ to $16 \mathrm{~cm}^{-1}$ at $250 \mathrm{~K}$, whilst for the $1842 \mathrm{~cm}^{-1}$ band, this is reduced from $26 \mathrm{~cm}^{-1}$ to $23 \mathrm{~cm}^{-1}$. In addition, some difference in the structure of the $\mathrm{P}, \mathrm{Q}$ and $\mathrm{R}$ branching of the $1741 \mathrm{~cm}^{-1}$ PAN band is evident with a sharpening of the associated Q branch and a difference in the relative intensities of the $\mathrm{P}$ and $\mathrm{R}$ branches with decreasing temperature. Furthermore, the $1842 \mathrm{~cm}^{-1}$ band shows a shift in the point of maximum band intensity to higher wavenumber with the observed band centre shifted by $1 \mathrm{~cm}^{-1}$ from $1841.5 \mathrm{~cm}^{-1}$, at $295 \mathrm{~K}$, to $1842.5 \mathrm{~cm}^{-1}$ at $250 \mathrm{~K}$.

The calculated peak absorption cross-sections are given in Table 3, with a comparison to room temperature data from Allen et al. (2005). Peak cross-sectional increases with decreasing temperature are in the range between $6 \%$ (for the $1842 \mathrm{~cm}^{-1}$ PAN band) and 30\% (for the $991 \mathrm{~cm}^{-1}$
PAN band) for all bands between $295 \mathrm{~K}$ and $250 \mathrm{~K}$, reflecting the increases in peak infrared absorptivity discussed earlier. Again, the relative uncertainty is less than $5 \%$ for the five principal absorption bands in this spectral range at all temperatures studied, although there is the possibility for some overlap within this uncertainty between the peak crosssections calculated at each temperature.

The observed narrowing of PAN absorption bands and the corresponding increase in peak infrared absorptivity with decreasing temperature for all bands is suggested to be predominantly due to changes in the thermal population distribution of rotational energy levels. Explanations of increases in integrated band strength with decreasing temperature for other heavy asymmetric top molecules, similar to those reported here for all but the 1741 and $1842 \mathrm{~cm}^{-1}$ PAN bands, include the effects of saturation of narrow lines (McDaniel et al., 1991) and contributions from temperature dependant anharmonicity terms to the band intensities (Yao and Overend, 1976; Wang et al., 2001). In our measurements, we are confident that the experimental conditions ensure that the former cannot occur due to the low optical densities observed, whereas resonance between the high density of ro-vibrational states giving rise to infrared absorption is certainly a possibility. The marked decrease $(28 \%)$ in the $1741 \mathrm{~cm}^{-1}$ integrated band intensity between 295 and $250 \mathrm{~K}$, and associated changes in the relative intensities of the P, Q an R branches, is consistent with an expected decrease in the population (at lower temperatures) of possible superimposed hot bands and combination bands.

Such subtleties of structure, together with differences in intensity could be important for accurate remote sensing of PAN in the colder atmosphere from infrared measurements of the atmosphere. Further measurements of PAN at temperatures between $200 \mathrm{~K}$ and $250 \mathrm{~K}$ would therefore be desirable, although challenging, requiring both long sample pathlengths and accurate measurement of PAN at very small sample pressures (due to low saturation vapour pressure).

\section{Conclusions}

Absorption cross-sections for PAN in the atmospherically important spectral range 550 to $1400 \mathrm{~cm}^{-1}$ at $273 \mathrm{~K}$ and $250 \mathrm{~K}$ have been calculated for the first time from twelve spectra of independent PAN samples at a spectral resolution of $0.25 \mathrm{~cm}^{-1}$. In addition, the 1600 to $2200 \mathrm{~cm}^{-1}$ spectral region has been surveyed at $250 \mathrm{~K}$.

Peak infrared absorptivities for all PAN bands are seen to increase with decreasing temperature with corresponding cross-sectional increases in the range $6 \%$ (for the strong $1842 \mathrm{~cm}^{-1}$ PAN band) and $30 \%$ (for the weak $991 \mathrm{~cm}^{-1}$ PAN band) at $250 \mathrm{~K}$ relative to those calculated at $295 \mathrm{~K}$ (using previously reported data by Allen et al. (2005). Furthermore, integrated band intensities are observed to increase for all but the 1741 and $1842 \mathrm{~cm}^{-1}$ PAN bands. Changes in 

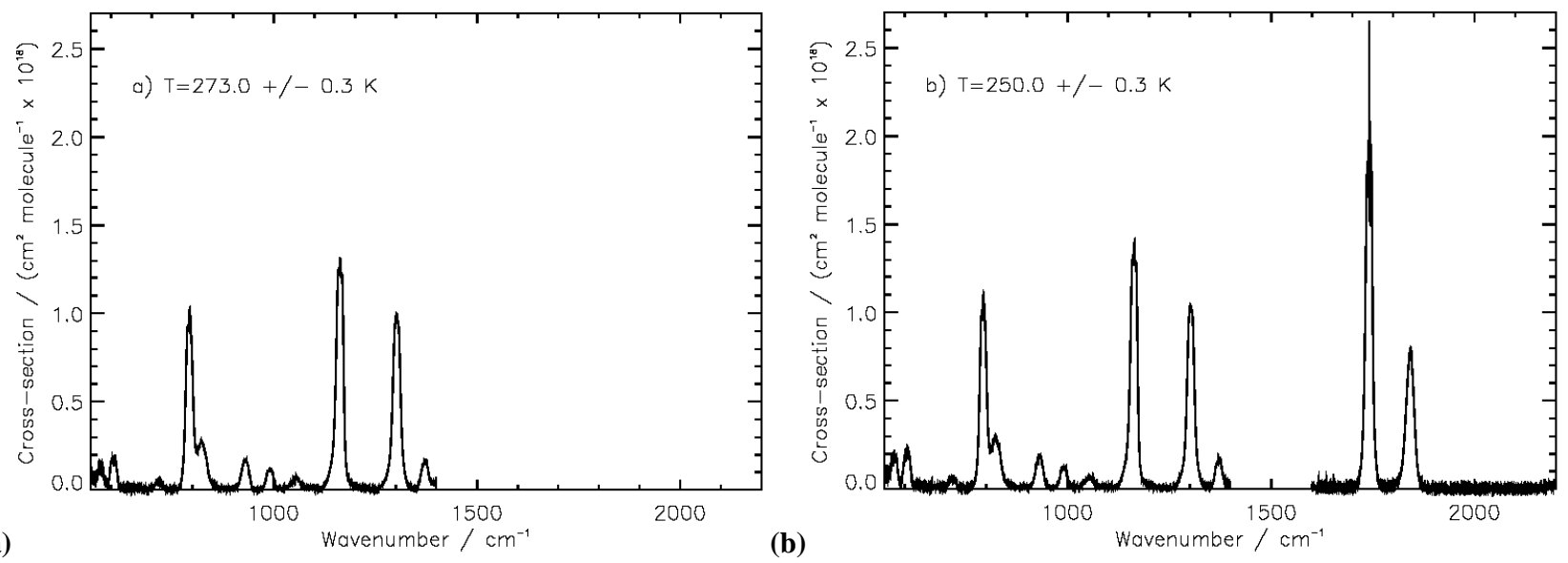

Fig. 1. PAN mid-infrared absorption cross-sections $\left(0.25 \mathrm{~cm}^{-1}\right.$ resolution) at sample temperatures of: (a) $273 \mathrm{~K} \pm 0.3 \mathrm{~K}$ (550 to $1400 \mathrm{~cm}^{-1}$ ); and (b) $250 \pm 0.3 \mathrm{~K}\left(550-1400 \mathrm{~cm}^{-1}, 1600-2000 \mathrm{~cm}^{-1}\right)$. Note: measurements at $273 \mathrm{~K}$ were not made above $1600 \mathrm{~cm}^{-1}$
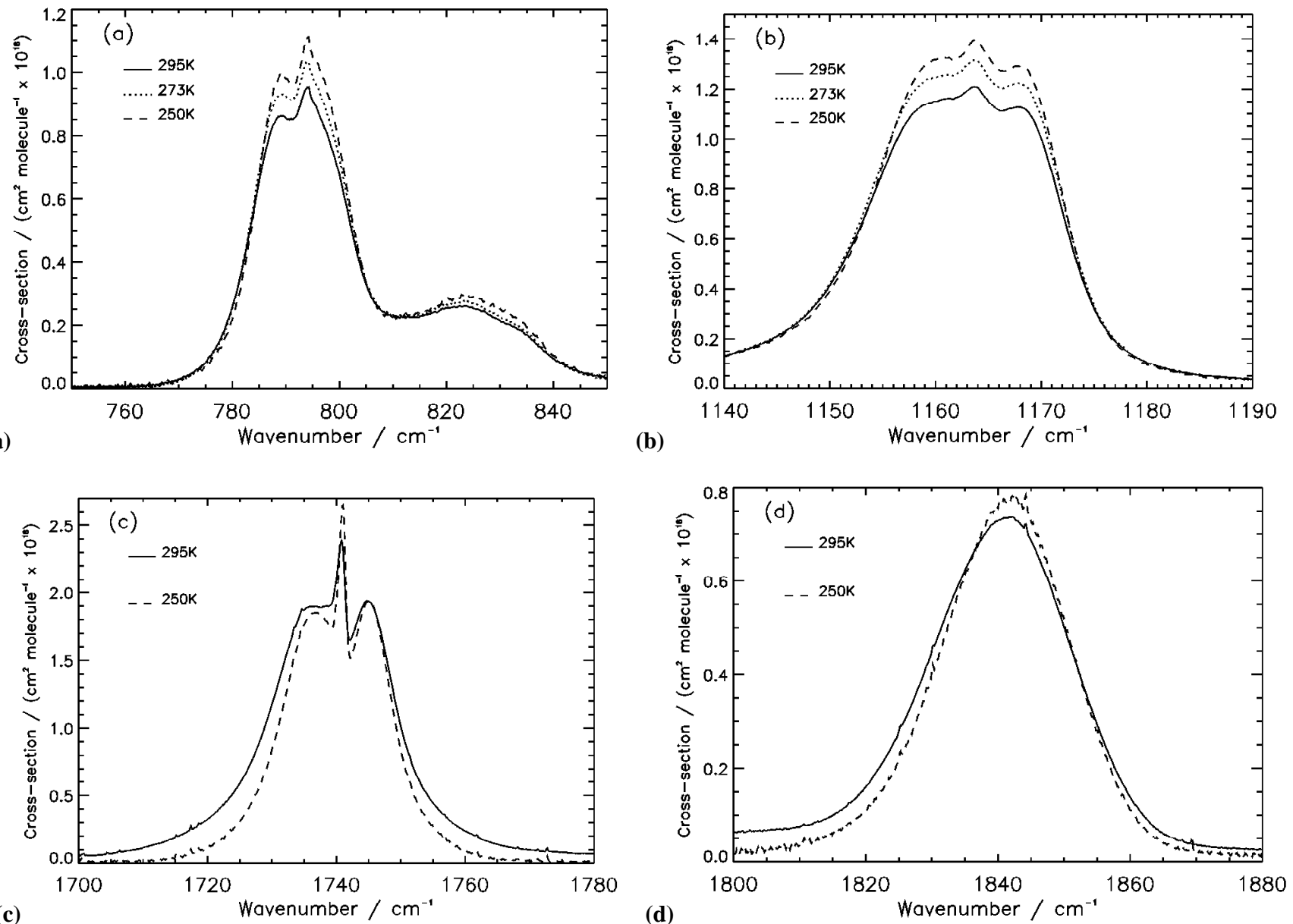

Fig. 2. A close up of the: (a) 794, (b) 1163, (c) 1741 and (d) $1842 \mathrm{~cm}^{-1}$ PAN bands showing temperature dependence at $295 \mathrm{~K}$ (solid line) $273 \mathrm{~K}$ (dotted line) and $250 \mathrm{~K}$ (dashed line). Note: $295 \mathrm{~K}$ data taken from Allen et al. (2005). 
integrated band intensities at $250 \mathrm{~K}$ relative to those at $295 \mathrm{~K}$ range from $-22 \%$ (for the $1741 \mathrm{~cm}^{-1}$ band) to $+16 \%$ (for the $991 \mathrm{~cm}^{-1}$ band). Relative uncertainty is typically better than $5 \%$ for the strong PAN bands. However, it is noted that due to the assigned uncertainty for each integrated band intensity there is the possibility of overlap at the extremes of the assigned error for intensities calculated at $250 \mathrm{~K}$ and $295 \mathrm{~K}$.

Structural differences in the principal PAN absorption bands are noted, with a marked narrowing of the 1741 and 1842 bands $\mathrm{cm}^{-1}$ with decreasing temperature. Also a sharpening of the $1742 \mathrm{~cm}^{-1}$ PAN band Q branch and a difference in the relative intensity of the $\mathrm{P}$ and $\mathrm{R}$ branches is also noted for this band. There is also evidence for a shift $\left(+1 \mathrm{~cm}^{-1}\right)$ in the point of peak intensity of the $1842 \mathrm{~cm}^{-1}$ band from $1841.5 \mathrm{~cm}^{-1}$ to $1842.5 \mathrm{~cm}^{-1}$. No significant broadening of PAN bands was observed with the addition of dry nitrogen gas (up to $500 \mathrm{mb}$ total pressure) to pure PAN samples.

In particular, the temperature dependence of the 794 and $1163 \mathrm{~cm}^{-1}$ PAN bands is of great importance in remotesensing applications due to their varying spectral influences in these atmospheric window regions at the colder temperatures of the free and upper troposphere. The measurement of these bands at three temperatures $(295 \mathrm{~K}, 273 \mathrm{~K}$ and $250 \mathrm{~K}$ ) gives greater confidence in their temperature dependence.

These new cross-sections accompany this work as an electronic supplement (http://www.atmos-chem-phys.org/ acp/5/3153/acp-5-3153-sp.zip) and complement PAN crosssectional data at room temperature $(295 \mathrm{~K})$ previously reported by Allen et al. (2005), together allowing a more accurate investigation of PAN throughout the troposphere.

Acknowledgements. The authors wish to thank the Natural Environment Research Council (NERC) for supporting G. Allen through grant ref: NER/T/S/2000/01087, and for access to the Molecular Spectroscopy Facility at the Rutherford Appleton Laboratory (RAL). R. G. Williams is thanked for providing technical support at the Rutherford Appleton Laboratory.

Edited by: A. Hofzumahaus

\section{References}

Allen, G., Remedios, J. J., Newnham, D. A., Smith, K. M., and Monks, P. S.: Improved mid-infrared cross-sections for peroxyacetyl nitrate (PAN) vapour, Atmos. Chem. Phys., 5, 47-56, 2005 ,

SRef-ID: 1680-7324/acp/2005-5-47.

Bernath, P. F., Boone, C., Walker, K., McLeod, S., Nassar, R.: The Atmospheric Chemistry Experiment (ACE): Mission Overview, Geophys. Res. Lett., 32, L15S01, doi:10.1029/2005GL022386, 2005.

Bruckmann, P. W. and Willner, H.: Infrared spectroscopic study of peroxyacetyl nitrate (PAN) and its decomposition products, Environ. Sci. Tech., 17, 352-357, 1983.
Chu, P. M., Grunther, F. R., Rhoderick, G. C., and Lafferty, W. J.: The NIST quantitative infrared database, J. Res. Nat. I, 104(1), 59-81, 1999.

Emmons L. K., Hauglustaine, D. A., Muller, J. F., Carroll, M. A., Brasseur, G. P., Brunner, D., Staehelin, J., Thouret, V., and Marenco, A.: Data composites of airborne observations of tropospheric ozone and its precursors, J. Geophys. Res., 105, 20497 20538, 2000.

Fischer, H. and Oelhaf, H.: Remote sensing of vertical profiles of atmospheric trace constituents with MIPAS limb-emission spectrometers, Appl. Opt., 35, 2787-2796, 1996.

Gaffney, J. S., Fajer, R., and Senum, G. I.: An improved procedure for high purity gaseous peroxyacetyl nitrate production: Use of heavy lipid solvents, Atmos. Environ., 18, 215-218, 1984.

McDaniel, A. H., Cantrell, C. A., Davidson, J. A., Shetter, R. E., and Calvert, J. G.: The temperature-dependent, infrared-absorption cross-sections for the chlorofluorocarbons - CFC-11, CFC-12, CFC-13, CFC-14, CFC-22, CFC-113, CFC-114, and CFC-115, J. Atmos. Chem, 12, 211-227, 1991.

Norton, R. H. and Beer, R.: New apodising functions for Fourier spectrometry, J. Opt. Soc. A., 66, 259-264, 1976.

Norton, R. H. and Beer, R.: New apodising functions for Fourier spectrometry - Erratum, J. Opt. Soc. A., 67, p. 419, 1977.

Richardson, R. L., Yang, H., and Griffiths, P. R.: Effects of Detector Nonlinearity on Spectra Measured on Three Commercial FT-IR Spectrometers, Appl. Spectrosc., 52(4), 572-578, 1998.

Roberts, J. M.: The atmospheric chemistry of organic nitrates, Atmos. Environ., Part A, 24A, 243-287, 1990.

Roberts, J. M., Flocke, F., Chen, G., et al.: Measurement of peroxycarboxylic nitric anhydrides (PANs) during the ITCT 2K2 aircraft intensive experiment, J. Geophys. Res., 109, D23S21, doi:10.1029/2004/JD004960, 2004.

Singh, H. B.: Reactive nitrogen in the troposphere - chemistry and transport of NOx and PAN, Environ. Sci. Technol., 21, 320-327, 1987.

Singh, H. B. and Hanst, P. L.: Peroxyacetyl nitrate (PAN) in the unpolluted atmosphere: An important reservoir for nitrogen oxides, Geophys. Res. Lett., 8, 941-944, 1981.

Talukdar, R. K., Burkholder, J. B., Schmoltner, A., Roberts, J. M., Wilson, R. R., and Ravishankara, A. R.: Investigation of he loss processes for peroxyacetyl nitrate in the atmosphere: UV photolysis and reaction with OH, J. Geophys. Res-A., 100, 14 163$14173,1995$.

Tanimoto, H., Hirokawa, J., Kajii, Y., and Akimoto, H.: A new measurement technique at parts per trillion by volume levels: Gas chromatography/negative ion chemical ionization mass spectrometry, J. Geophys. Res., 104, 21 343-21 354, 1999.

Tsalkani, N. and Toupance, G.: Infrared absorptivities and integrated band intensities for gaseous peroxyacetyl nitrate (PAN), Atmos. Environ., 23, 1849-1854, 1989.

Wang, W. F., Stevenson, A., Reuter, D. C., and Sirota, J. M.: Absolute band intensities of acetone $\left.\left[\left(\mathrm{CH}_{3}\right)_{2} \mathrm{CO}\right)\right]$ in the infrared region $830-3200 \mathrm{~cm}^{-1}$ at low and room temperatures, Spectr. Acta, 57, 1603-1610, 2001.

Yao, S. J. and Overend, J.: Vibrational intensities: Effect of anharmonicity on temperature-dependence of integrated intensities, Spectr. Acta, 32(5), 1059-1065, 1976. 